\title{
Bioavailability of Vitamin D from Fortified Process Cheese and Effects on Vitamin D Status in the Elderly*
}

\author{
J. L. Johnson, ${ }^{1}$ V. V. Mistry, ${ }^{1}$ M. D. Vukovich, ${ }^{2}$ T. Hogie-Lorenzen, ${ }^{3}$ \\ B. W. Hollis, ${ }^{4}$ and B. L. Specker ${ }^{3}$ \\ ${ }^{1}$ Dairy Science Department, ${ }^{2}$ Exercise Physiology Laboratory, and \\ ${ }^{3}$ Ethel Austin Martin Endowed Program in Human Nutrition, \\ South Dakota State University, Brookings 57007 \\ ${ }^{4}$ Department of Pediatrics, Medical University of South Carolina, Charleston 29425
}

\begin{abstract}
We conducted 2 studies to determine the effect of vitamin D-fortified cheese on vitamin $\mathrm{D}$ status and the bioavailability of vitamin $\mathrm{D}$ in cheese. The first study was designed to determine the effect of 2 mo of daily consumption of vitamin $\mathrm{D}_{3}$-fortified (600 IU/d) process cheese on serum 25-hydroxyvitamin D (25-OHD), parathyroid hormone (PTH), and osteocalcin (OC) concentrations among 100 older ( $\geq 60 \mathrm{yr})$ men and women. Participants were randomized to receive vitamin Dfortified cheese, nonfortified cheese, or no cheese. Serum levels of 25-OHD, $\mathrm{PTH}$, and $\mathrm{OC}$ were measured at the beginning and end of the study. There were no differences in 25-OHD, PTH, or OC after 2 mo of fortified cheese intake. The vitamin D-fortified cheese group had a greater decrease in 25-OHD than other groups, due to higher baseline 25-OHD. A second study was conducted to determine whether the bioavailability of vitamin $\mathrm{D}_{2}$ in cheese (delivering $5880 \mathrm{IU}$ of vitamin $\mathrm{D}_{2} / 56.7$-g serving) and water (delivering 32,750 IU/250 $\mathrm{mL}$ ) is similar and whether absorption differs between younger and older adults. The second study was a crossover trial involving 2 groups of 4 participants each (younger and older group) that received single acute feedings of either vitamin $\mathrm{D}_{2}$-fortified cheese or water. Serial blood measurements were taken over $24 \mathrm{~h}$ following the acute feeding. Peak serum vitamin $\mathrm{D}$ and area under the curve were similar between younger ( 23 to $50 \mathrm{yr}$ ) and older (72 to $84 \mathrm{yr}$ ) adults, and vitamin $\mathrm{D}_{2}$ was absorbed more efficiently from cheese than from water. These studies demonstrated that vitamin $\mathrm{D}$ in fortified process cheese is bioavailable, and that young
\end{abstract}

Received March 17, 2005.

Accepted April 15, 2005.

Corresponding author: V. V. Mistry; e-mail: vikram.mistry@ sdstate.edu.

*Published with the approval of director of the South Dakota Agricultural Experiment Station as Publication Number 3409 of the Journal Series. This research was sponsored, in part, by the National Dairy Council, Rosemont, IL. and older adults have similar absorption. Among older individuals, consuming $600 \mathrm{IU}$ of vitamin $\mathrm{D}_{3}$ daily from cheese for 2 mo was insufficient to increase serum 25OHD during limited sunlight exposure.

(Key words: process cheese, vitamin D, elderly, bioavailability)

Abbreviation key: $\mathbf{A I}=$ adequate intake, 25-OHD = 25-hydroxyvitamin D, OC = osteocalcin, $\mathbf{P T H}=$ parathyroid hormone.

\section{INTRODUCTION}

Vitamin D is essential in maintaining blood calcium concentrations within a narrow physiological range. Although vitamin $\mathrm{D}$ is typically classified as a fat-soluble vitamin, it actually functions as a hormone in the body (Dabek, 1990). Vitamin D is not technically classified as an essential nutrient because it can be manufactured by the body through exposure of the skin to the ultraviolet rays of the sun. Exposure to ultraviolet radiation converts 7-dehydrocholesterol to previtamin $\mathrm{D}_{3}$, which is then converted to vitamin $\mathrm{D}_{3}$ through thermal isomerization. Vitamin $D_{3}$ is transported to the liver where it is hydroxylated to 25-hydroxyvitamin D (25-OHD). Serum concentrations of 25-OHD are often used as an indicator of vitamin D status.

There are limited dietary sources of vitamin $\mathrm{D}$, including cod liver oil, fatty fish such as salmon, as well as small amounts found in egg yolks (Holmes and Kumerow, 1983). Fortified dietary sources of vitamin D include milk and, more recently, some juice products. Regular exposure to sunlight is the usual way for meeting vitamin D requirements. If one's exposure to sunlight is limited, vitamin D deficiency may develop, and the need for supplementation, either as an oral supplement or through innovations in food fortification is compelling.

It is widely accepted that adequate amounts of vitamin D are crucial for healthy bone development, maintenance of bone density and bone strength, and prevention of osteoporosis. A deficiency of vitamin D may re- 
sult in osteomalacia and rickets. Osteomalacia refers to the softening of the bones in adults, and rickets is the syndrome that affects deficient children, causing bowed legs, joint deformities, and poor growth and development (Bronner, 1976). The needed amount of vitamin D is expressed as an adequate intake (AI), rather than a required daily amount, because it is difficult to quantify the amount of vitamin $\mathrm{D}$ that is produced by the body with exposure to sunlight. The AI for individuals under age 50 is $200 \mathrm{IU} / \mathrm{d}$, for 51 to $70 \mathrm{yr}$ olds is 400 $\mathrm{IU} / \mathrm{d}$, and for those over $70 \mathrm{yr}$ of age is $600 \mathrm{IU} / \mathrm{d}$ (Standing Committee on the Scientific Evaluation of Dietary Reference Intakes, 1997).

The elderly population is at increased risk of developing vitamin D deficiency and associated bone disease due to decreased sun exposure and a reduced ability to adequately synthesize vitamin D endogenously (Gloth et al., 1995). In addition, their dietary intakes may be lower because of declining milk consumption (Kevin, 1997). However, it is not merely the elderly population who should consider supplementation. Vitamin D supplementation is a feasible option for those individuals living in northern cities, particularly during the winter months, when their exposure to sunlight is significantly reduced.

Due to the concern for adequate intakes of vitamin $\mathrm{D}$ and the change in food consumption trends, it is apparent that there is a need for a larger range of food products that can provide the necessary amounts of vitamin $\mathrm{D}$ in the diet. A previous study was conducted to develop techniques for manufacturing pasteurized process cheese fortified with vitamin D (Upreti et al., 2002). The objectives of this research were to determine the effect of consumption of vitamin D-fortified process cheese on serum 25-hydroxyvitamin D (25-OHD), parathyroid hormone (PTH), and osteocalcin (OC) concentrations among the elderly, and the bioavailability of vitamin $\mathrm{D}$ from fortified process cheese and water.

\section{MATERIALS AND METHODS}

\section{Study 1}

One hundred ten older individuals ( $\geq 60 \mathrm{yr}$ ) were enrolled in a partially double-blind, randomized clinical trial designed to determine the effect of 2 mo of daily vitamin D-fortified process cheese consumption, delivering $600 \mathrm{IU}$ of vitamin $\mathrm{D}$ per day, on changes in serum 25-OHD, PTH, and OC concentrations. The intervention groups consisted of one group that received $85 \mathrm{~g}$ of process cheese fortified with vitamin $\mathrm{D}_{3}$ (delivering $600 \mathrm{IU} / \mathrm{d}$ ), one group that received process cheese without vitamin $\mathrm{D}_{3}$, and a control group that received no process cheese. If couples were enrolled in the study, randomization was for the pair to avoid confusion that might occur if each participant were randomized to a different cheese group. The placebo group (process cheese without addition of vitamin D) was included to allow for the determination of the specific effect of vitamin D fortification. The control group (no cheese) was included to allow for the determination of the overall effect of the process cheese, with its high protein, calcium, and phosphorus content, on the outcome measurements. Compliance was measured by having participants save all remaining process cheese they were unable to eat, which was then picked up by study personnel when the new cheese was delivered every $2 \mathrm{wk}$. The leftover cheese was returned to the South Dakota State University dairy plant to be weighed and recorded on each participant's chart.

Subjects were recruited from local community organizations. Inclusion criteria included no routine use of vitamin or mineral supplements, a total serum cholesterol at baseline of less than $240 \mathrm{mg} / \mathrm{dL}$, ability to consume and digest cheese without gastrointestinal difficulty, and willingness and ability to remain in the Great Plains region of the country during the study period. The study was conducted during the winter months to minimize sunlight exposure.

Fasting blood samples were collected from all study participants at the time of enrollment and after the 2mo intervention. A $10-\mathrm{mL}$ serum sample was drawn, separated, aliquoted, and frozen at $-70^{\circ} \mathrm{C}$ for the duration of the study, at which point the samples were analyzed in one batch for total 25-OHD $\left(25-\mathrm{OHD}_{2}+25\right.$ $\mathrm{OHD}_{3}$; Hollis et al., 1993) and PTH concentrations, using the DiaSorin kit (normal range for PTH of 13 to $54 \mathrm{pg} / \mathrm{mL}$ ), by the laboratory of Bruce Hollis (Medical University of South Carolina). Osteocalcin concentrations were measured by Clinical Laboratories of the Midwest in Sioux Falls, SD. A blood lipid panel was obtained to determine the effect of cheese consumption on blood lipids.

Three-day diet records were completed by each of the participants at baseline, including each individual's use of vitamins or supplements. The records were sent to each subject with instructions and a list of size estimates to provide approximate food intake amounts. Subjects were asked to record their diets during 2 weekdays and 1 weekend day and return the record to study personnel. The diet records were reviewed and analyzed using Nutritionist Pro software (1998 edition; First Data Bank, San Bruno, CA). Mean total vitamin D intakes were calculated as the sum of dietary vitamin $D$ from the 3-d record at baseline and the average amount obtained from cheese. Participants were weighed (SECA digital scale, model \#770; SECA, Hanover, MD) to the nearest $0.1 \mathrm{~kg}$, and changes were compared among groups to determine if there was a significant 
weight gain from consumption of the relatively higher percentage fat cheese ( $35.4 \%$ fat). Diet records were not collected during the study and it was assumed that intake at baseline was equivalent to intake during intervention. Participants were instructed to continue their normal activity and eating patterns throughout the study. Although participants were asked not to substitute the cheese for other foods, it appeared, from informal discussions, that many subjects substituted the cheese as their protein source instead of meats.

Vitamin $\mathrm{D}_{3}$ is available commercially for fortification purposes in both water- and fat-dispersible forms. Using previously developed methods (Upreti et al., 2002), 36 batches of process cheese were manufactured, 18 supplemented with water-dispersible vitamin $\mathrm{D}_{3}$ (Dry Vitamin $\mathrm{D}_{3}, 100$ GFP Kosher, BASF Corporation, Edison, NJ), and 18 without vitamin D. Vitamin D was added at the amounts necessary to obtain a vitamin $\mathrm{D}_{3}$ concentration of 200 IU per 28.3-g serving of cheese. A known amount of water-dispersible vitamin $D_{3}$ was dissolved in distilled water. Dilutions were made in distilled water such that each $1 \mathrm{~mL}$ of fortifying solution corresponded to the appropriate vitamin $\mathrm{D}_{3}$ fortification level for $0.454 \mathrm{~kg}(1 \mathrm{lb})$ of process cheese. For example, $3.059 \mathrm{~g}$ of $106,000 \mathrm{IU} / \mathrm{g}$ of water-dispersible vitamin $\mathrm{D}_{3}$ fortificant was dissolved in $100 \mathrm{~mL}$ of distilled water, and $1 \mathrm{~mL}$ of this solution was added to $0.454 \mathrm{~kg}(1 \mathrm{lb})$ of process cheese to obtain the desired vitamin $\mathrm{D}_{3}$ level of 200 IU per 28.3-g serving of cheese. Four to five grams of process cheese from each batch were used for analysis of vitamin $\mathrm{D}_{3}$ content, which included heated saponification, liquid-liquid extraction using water-immiscible organic solvents (ether extraction), solid-phase extraction using silica-packed cartridges under negative pressure, and quantification of vitamin $\mathrm{D}_{3}$ using an HPLC apparatus. The HPLC procedure used a detector at $254 \mathrm{~nm}$ and a mobile phase consisting of a methanol:acetonitrile ratio of 70:30, which resulted in a retention time of approximately $9 \mathrm{~min}$ for the vitamin $\mathrm{D}_{3}$ peak. To minimize variability in results due to the many steps in the vitamin $\mathrm{D}_{3}$ quantification, a standard curve was developed by adding $1 \mathrm{~mL}$ of a standard vitamin $\mathrm{D}_{3}$ solution to approximately $5 \mathrm{~g}$ of shredded, unfortified process cheese at varying levels. The samples were run through the same format of analysis and the area of the vitamin $\mathrm{D}_{3}$ peak was adjusted by deducting the area produced by the unfortified process cheese and plotted against the known concentration of vitamin $\mathrm{D}_{3}$ (Upreti et al., 2002). Process cheeses with no added vitamin $\mathrm{D}_{3}$ showed no measurable vitamin $\mathrm{D}_{3}$, whereas those that were fortified averaged 200.14 IU of vitamin $\mathrm{D}_{3}$ per 28.3-g serving. The mean moisture, fat, and protein of process cheeses without vitamin $\mathrm{D}_{3}$ was 39.7 , 35.1 , and $19.7 \%$, respectively, whereas that of process cheeses with vitamin $\mathrm{D}_{3}$ was $39.5,33.8$, and $19.5 \%$ respectively, making them legal according to US standards of identity.

One-way ANOVA was used in testing hypotheses pertaining to study 1 . If significant differences were observed among groups, the Tukey-Kramer HSD (honestly significant difference) was used to determine which groups differed. Because of non-normality of serum PTH concentrations, appropriate nonparametric tests were also conducted. Similar results were obtained and only the parametric versions are presented.

\section{Study 2}

Based upon the results of the first feeding trial, an additional randomized crossover trial was conducted to further investigate the bioavailability of vitamin $D_{2}$ (which has a similar bioavailability as vitamin $\mathrm{D}_{3}$ ) and to determine the absorption of vitamin $\mathrm{D}_{2}$ from process cheese (delivering $5880 \mathrm{IU}$ of vitamin $\mathrm{D}_{2} / 57$-g serving) compared with absorption from a different vehicle, a fortified water dilution (delivering 32,750 IU/250 mL). The targeted amount in cheese was 10,000 IU per 57g serving and 10,000 IU per $250-\mathrm{mL}$ serving of water. Vitamin $\mathrm{D}_{2}$ was used to prevent interference from sunlight exposure. Two groups of 4 participants each were enrolled: the first group consisted of individuals aged 23 to $50 \mathrm{yr}$ and the second group consisted of individuals aged 72 to 84 . The 23 to 50 yr age group was recruited from the South Dakota State University campus. The 72 to 84 yr old subjects were participants from study 1 .

Each individual initially received a single acute feeding, with the order randomly determined, of either process cheese or water that had been fortified with a known amount of water-dispersible vitamin $\mathrm{D}_{2}$ solution (Freeman Industries, Tuckahoe, NY). Fortified process cheese or the vitamin $\mathrm{D}$ water dilution was given to each study participant between 0800 and $0900 \mathrm{~h}$ after an overnight fast on d 0 . Blood samples were collected before consuming the vehicle, and at 6,12 , and $24 \mathrm{~h}$ postconsumption. On d 14, the procedures were repeated but with the other delivery vehicle. Blood samples were drawn by venipuncture, spun down, and serum was frozen at $-70^{\circ} \mathrm{C}$ until the study was completed. The serum was then sent to Bruce Hollis' laboratory at the Medical University of South Carolina for determination of vitamin $D_{2}$ concentrations as previously reported (Hollis et al., 1993). Area under the curve and peak serum concentration were then compared using 2-way ANOVA [main effects of age group and food (process cheese vs. water)]. Peak serum concentrations were expressed per 10,000 IU of vitamin $\mathrm{D}_{2}$ administered. Written informed consent was obtained from each participant and approval was obtained for each study from 
JOHNSON ET AL.

Table 1. Baseline characteristics and changes in blood measurements by intervention group. ${ }^{1}$

\begin{tabular}{|c|c|c|c|c|}
\hline Characteristic & $\begin{array}{l}\text { Vitamin } \\
\text { D-fortified } \\
\text { process cheese }\end{array}$ & $\begin{array}{l}\text { Nonfortified } \\
\text { process cheese }\end{array}$ & $\begin{array}{l}\text { No process } \\
\text { cheese }\end{array}$ & $P$ value \\
\hline Number enrolled & 35 & 37 & 38 & \\
\hline Number completed (male/female) & $13 / 20$ & $14 / 20$ & $10 / 23$ & \\
\hline Height $(\mathrm{cm})$ & $167.4 \pm 1.6$ & $168.4 \pm 1.7$ & $167.4 \pm 1.4$ & NS \\
\hline \multicolumn{5}{|l|}{ Weight $(\mathrm{kg})$} \\
\hline Baseline & $81.3 \pm 2.5$ & $79.9 \pm 3.0$ & $75.6 \pm 3.1$ & NS \\
\hline Final & $81.6 \pm 2.4$ & $82.4 \pm 2.8$ & $75.8 \pm 3.1$ & NS \\
\hline Change & $0.3 \pm 0.3$ & $0.1 \pm 0.2$ & $0.2 \pm 0.4$ & NS \\
\hline Calcium intake/d (mg) & $1206 \pm 94$ & $1221 \pm 94$ & $1064 \pm 94$ & NS \\
\hline Vitamin D intake/d (IU) & $443 \pm 49$ & $529 \pm 69^{\mathrm{a}}$ & $340 \pm 38^{\mathrm{a}}$ & 0.05 \\
\hline Vitamin D intake from cheese/d (IU) & $587 \pm 8^{\mathrm{ab}}$ & $0^{\mathrm{a}}$ & $0^{\mathrm{b}}$ & 0.001 \\
\hline Total vitamin D intake/d (IU) & $1034 \pm 54^{\mathrm{ab}}$ & $529 \pm 69^{\mathrm{ac}}$ & $340 \pm 38^{\mathrm{bc}}$ & 0.05 \\
\hline \multicolumn{5}{|l|}{ Biochemical measurements } \\
\hline \multicolumn{5}{|l|}{ 25-Hydroxyvitamin D (ng/mL) } \\
\hline Baseline & $23 \pm 1.4^{\mathrm{a}}$ & $20 \pm 1.2$ & $18 \pm 1.3^{\mathrm{a}}$ & 0.04 \\
\hline Final & $21 \pm 1.4$ & $22 \pm 1.1$ & $19 \pm 1.2$ & $\mathrm{NS}$ \\
\hline Change & $-2.4 \pm 0.8^{\mathrm{ab}}$ & $1.4 \pm 0.5^{\mathrm{a}}$ & $0.3 \pm 0.7^{\mathrm{b}}$ & 0.001 \\
\hline \multicolumn{5}{|l|}{ Parathyroid hormone (pg/mL) } \\
\hline Baseline & $36 \pm 3$ & $31 \pm 2$ & $32 \pm 2$ & NS \\
\hline Final & $36 \pm 4$ & $28 \pm 2$ & $32 \pm 2$ & NS \\
\hline Change & $-0.1 \pm 2$ & $-3 \pm 2$ & $0.6 \pm 1$ & NS \\
\hline \multicolumn{5}{|l|}{ Osteocalcin (ng/mL) } \\
\hline Baseline & $16 \pm 1$ & $16 \pm 1$ & $18 \pm 1$ & NS \\
\hline Final & $15 \pm 1$ & $13 \pm 1$ & $16 \pm 1$ & NS \\
\hline Change & $-1 \pm 1$ & $-4 \pm 1$ & $-2 \pm 1$ & $\mathrm{NS}$ \\
\hline \multicolumn{5}{|l|}{ Cholesterol (mg/dL) } \\
\hline Baseline & $193 \pm 5$ & $193 \pm 5$ & $196 \pm 5$ & NS \\
\hline Final & $194 \pm 6$ & $199 \pm 6$ & $191 \pm 5$ & NS \\
\hline Change & $1 \pm 3$ & $4 \pm 5$ & $-6 \pm 3$ & NS \\
\hline
\end{tabular}

${ }^{\mathrm{a}, \mathrm{b}, \mathrm{c}}$ Means with similar superscripts are different from each other.

${ }^{1}$ Data are mean \pm SEM. Vitamin D-fortified process cheese group received $85 \mathrm{~g}$ of process cheese fortified with vitamin $\mathrm{D}_{3}$, delivering $600 \mathrm{IU} / \mathrm{d}$; Nonfortified process cheese group received $85 \mathrm{~g}$ of process cheese with no added vitamin D; No process cheese group was control and received no process cheese.

the South Dakota State University Institutional Review Board.

\section{RESULTS}

\section{Study 1}

There were 35 subjects enrolled in the vitamin Dfortified process cheese group, 37 in the nonfortified process cheese group, and 38 in the control group. Of the 110 individuals who enrolled in the study, 100 (91\%) completed: 33 in the vitamin D fortified cheese group, 34 in the nonfortified cheese group, and 33 in the control group. The reasons stated for early withdrawal included going on vacation $(\mathrm{n}=2)$, gastrointestinal problems $(\mathrm{n}=2)$, doctor's advice $(\mathrm{n}=3)$, medication use $(\mathrm{n}=$ $2)$, and a dislike for the saltiness of the cheese $(n=1)$. Overall compliance of consumption of the full $85 \mathrm{~g}$ of cheese per day was high at $96.2 \%$ with no difference in compliance between the 2 cheese groups.

The 3 blood measurements that were monitored at the beginning and end of the study were total $25-\mathrm{OHD}$, PTH, and OC (Table 1). The nonfortified cheese group, with a mean dietary vitamin D intake per day of 529 \pm 69 IU (baseline vitamin D intake) had an overall increase in serum 25-OHD concentrations of $1.4 \pm 0.5$ (SD) $\mathrm{ng} / \mathrm{mL}$ (change different from $0, P=0.01$ ). The vitamin D-fortified cheese group, which had a mean total vitamin D intake per day of $1034 \pm 54 \mathrm{IU}$ (sum of baseline intake of vitamin $\mathrm{D}$ and intake from cheese), surprisingly showed a decrease in serum 25-OHD concentrations [decrease of $2.4 \pm 0.8 \mathrm{ng} / \mathrm{mL}$ (different from 0 at $P<0.001$ )]. The no cheese group had a mean dietary vitamin D intake per day of $340 \pm 38$ IU (baseline vitamin D intake) and showed the lowest 25-OHD concentrations at both the beginning and end of the study, with a nonsignificant change of $0.3 \pm 0.7 \mathrm{ng} / \mathrm{mL}$. There were significant differences among groups in baseline 25-OHD concentrations $(P=0.04)$, with the vitamin Dfortified cheese group having significantly higher serum 25-OHD concentrations than the no cheese group. The overall changes in 25-OHD concentrations were also different among groups $(P<0.001)$ : the vitamin $\mathrm{D}$-fortified cheese group had a greater decrease in 25-OHD than both the nonfortified cheese group and the no cheese groups $(P<0.05)$, but there were no differences among groups in serum $25-\mathrm{OHD}$ at study completion. 


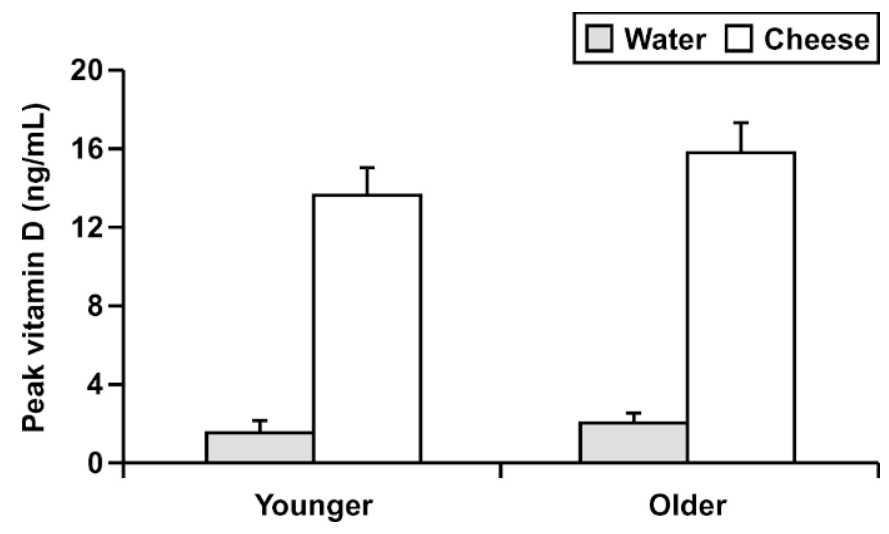

Figure 1. Mean peak serum vitamin $\mathrm{D}_{2}$ from vitamin $\mathrm{D}$-fortified cheese and vitamin D-fortified water among young and older adults.

None of the groups had a significant change from baseline in serum PTH concentrations (Table 1); and PTH concentrations at baseline and completion, and change in PTH during the study were similar among the intervention groups. Serum OC concentrations among the 3 groups demonstrated an average decrease of $3 \mathrm{ng} / \mathrm{mL}$ (different from $0, P=0.001$ ). The nonfortified cheese group exhibited the largest decrease of $4 \pm 1 \mathrm{ng} /$ $\mathrm{mL}$ (different from $0, P=0.004$ ), whereas neither the vitamin D-fortified cheese group nor the no cheese group had significant changes in OC. There were no differences in baseline, final, or changes in OC concentrations among the 3 intervention groups.

In addition to the 3 variables that were monitored to examine vitamin D status, cholesterol concentrations were measured at the beginning and end of the study (Table 1). Cholesterol concentrations among the 3 groups showed an overall decrease of $0.6 \mathrm{mg} / \mathrm{dL}$. Neither of the cheese groups had changes in cholesterol during the course of the study (both, $P>0.05$ ). The no cheese group had a significant decrease in cholesterol concentration $(6 \pm 3 \mathrm{mg} / \mathrm{dL}$, different from 0 at $P=0.05)$. There were no differences in baseline, study completion, or cholesterol change among the 3 intervention groups.

\section{Study 2}

The overall mean peak serum vitamin $\mathrm{D}_{2}$ concentration from process cheese was $15 \pm 1 \mathrm{ng} / \mathrm{mL}$ per 10,000 $\mathrm{IU}$; and that from the fortified water dilution was significantly lower at $2 \pm 0.4 \mathrm{ng} / \mathrm{mL}$ per $10,000 \mathrm{IU}(P<$ 0.001). The peak serum vitamin $D_{2}$ concentrations from both process cheese and water were similar among the younger and older groups (Figure 1).

The area under the curve for process cheese was 89 \pm 7 , which was higher than that observed for the vitamin D-fortified water dilution (63 $\pm 2, P=0.03)$. The mean area under the curve for vitamin $\mathrm{D}_{2}$ absorption from process cheese was similar between the younger and older populations, with means of $83 \pm 11$ and $96 \pm$ 6 , respectively. The mean area under the curve based upon vitamin $\mathrm{D}_{2}$ absorption from water also was similar between the younger and older populations $(60 \pm 20$ and $66 \pm 25$, respectively). Power calculations could not be performed because the observed difference was opposite of what was expected.

\section{DISCUSSION}

A primary concern in the fortification of foods is that the majority of the fortificant be recovered rather than destroyed during manufacturing and storage. A recent study demonstrated that pasteurized process cheese could be successfully fortified with vitamin $\mathrm{D}$ with minimal losses during manufacture or storage (Upreti et al., 2002). The present study was designed to determine whether vitamin $\mathrm{D}$ from such cheeses is bioavailable when the cheese is consumed.

We found that vitamin $\mathrm{D}$ in fortified process cheese is indeed bioavailable, but that among the elderly, consuming $600 \mathrm{IU}$ of vitamin D daily from fortified process cheese for 2 mo was insufficient to increase serum total 25-OHD concentrations. Although we observed a decrease in serum 25-OHD concentrations among the vitamin D-fortified cheese group, we speculate that this was due to the higher baseline serum 25-OHD concentrations. We could have ensured that serum 25-OHD concentrations were similar among groups at baseline by analyzing the samples before randomization, but we did not do this. Rather, we chose to analyze the serum samples in one batch after study completion to minimize between-assay variability, which can be significant with serum 25-OHD measurements. One of the advantages to randomized trials is that factors or variables should theoretically be similar at baseline among the different treatment groups. There are times, however, when randomization does not achieve this goal, as observed in the current study. The change in serum 25-OHD concentration of $2 \mathrm{ng} / \mathrm{mL}$ among the fortified cheese group, although statistically significant, is not clinically significant. The range of serum 25-OHD concentrations in middle-aged adults living in Omaha, NE, in October is 24 to $32 \mathrm{ng} / \mathrm{mL}$ (Heaney et al., 2003a). The lower limit of detection is $2.8 \mathrm{ng} / \mathrm{mL}$ and the normal range in October is 10 to $42 \mathrm{ng} / \mathrm{mL}$ (mean of $26 \mathrm{ng} / \mathrm{mL}$ ). Subjects receiving pharmacological doses of vitamin D were found to have a mean of $145 \mathrm{ng} / \mathrm{mL}$, with a range of 92 to $202 \mathrm{ng} / \mathrm{mL}$ (Hollis et al., 1993). The PTH and OC results and lack of differences among groups are consistent with the minimal changes we observed in serum 25-OHD concentrations. 
Our observations support a study that was conducted during the winter months of 2 successive years involving 67 middle-aged men who received daily oral doses of vitamin $\mathrm{D}_{3}$ at levels of $0,1000,5000$, and 10,000 IU (Heaney et al., 2003a). This study showed that for every 40-IU increment of vitamin $\mathrm{D}_{3}$ administered per day, total serum 25-OHD at equilibrium was higher by 0.28 $\mathrm{ng} / \mathrm{mL}(0.70 \mathrm{nmol} / \mathrm{L})$. Based on these estimates, we would expect that an additional $600 \mathrm{IU} / \mathrm{d}$ of vitamin $\mathrm{D}$ would lead to an estimated increase in serum 25-OHD concentration of approximately $4 \mathrm{ng} / \mathrm{mL}(10.5 \mathrm{nmol} / \mathrm{L})$. Heaney and coworkers concluded that adult men use between 3000 and 5000 IU of cholecalciferol per day, which is far above the current recommended adequate vitamin D intake (Heaney et al., 2003a).

One concern is the potential difference in bioavailability between vitamin $\mathrm{D}_{2}$ and vitamin $\mathrm{D}_{3}$. The absorption of vitamin $D_{2}$ and $D_{3}$ appear to be similar based on peak serum vitamin $\mathrm{D}$ concentrations following single oral dosings (Armas et al., 2004). Both vitamin $\mathrm{D}_{2}$ and $\mathrm{D}_{3}$ produce similar initial increases in serum 25OHD concentrations, but 25-OHD continues to increase in vitamin $\mathrm{D}_{3}$-treated subjects, whereas 25 -OHD falls rapidly in vitamin $\mathrm{D}_{2}$-treated subjects. These findings support previous work showing that $14 \mathrm{~d}$ of vitamin $\mathrm{D}_{3}$ supplementation lead to greater increases in serum 25OHD concentrations than supplementation with equivalent doses of vitamin $\mathrm{D}_{2}$ (Trang et al., 1998).

Our finding that $600 \mathrm{IU}$ of vitamin $\mathrm{D} / \mathrm{d}$ did not maintain serum total 25-OHD concentrations in the elderly is consistent with previous reports (Vieth et al., 2001; Heaney et al., 2003a). Vieth et al. (2001) reported values for the equilibrium increment of $0.5 \mathrm{ng} / \mathrm{mL}$ for a 1000 IU/d dose, and $3 \mathrm{ng} / \mathrm{mL}$ for a $4000 \mathrm{IU} / \mathrm{d}$ dose. The latter study is further evidence supporting the possibility that the current $\mathrm{AI}$ recommendations for vitamin $\mathrm{D}$ are too low. The dilemma in establishing an AI for vitamin D lies in the variability of vitamin D synthesis, use, and environmental discrepancies between individuals. We have shown that the current recommendation for healthy elderly men and women of an AI of $15 \mu \mathrm{g}$ (600 IU) per day is not sufficient to increase serum 25-OHD concentrations during winter at northern latitudes.

An early study by Harris and coworkers reported a smaller increase in serum 25-OHD concentrations following the administration of $1800 \mathrm{IU} / \mathrm{d}$ for $3 \mathrm{wk}$ among younger (aged 22 to $28 \mathrm{yr}$ ) vs. older men (65 to $73 \mathrm{yr}$ ), and they suggested that vitamin $\mathrm{D}$ absorption was greater in younger vs. older adults (Harris et al., 1999). However, we found that elderly individuals absorb vitamin $\mathrm{D}$ as efficiently as younger individuals from both process cheese and from a water dilution. These findings support a later study by Harris and coworkers that was conducted during an 8-wk period in the winter involving 25 young men (18 to $35 \mathrm{yr}$ of age) and 25 older men (62 to $79 \mathrm{yr}$ of age) who were supplemented with $800 \mathrm{IU}$ vitamin $\mathrm{D}_{3}$ per day or assigned to a control group (Harris and Dawson-Hughes, 2002). They found that, regardless of the age of the subject, the supplemented group had greater 25-OHD concentrations at study completion, and the magnitude of the increase was identical between the 2 age groups. Therefore, the researchers concluded that there is no apparent age-related impairment among men in the absorption or metabolism of orally dosed vitamin $\mathrm{D}_{3}$ when taken for at least 8 wk (Harris et al., 1999). Thus, in conjunction with our findings, we do not feel there is sufficient evidence to state that older individuals have lower vitamin $\mathrm{D}$ absorption than do younger individuals. Heaney and coworkers recently reported that serum $25-\mathrm{OHD}$ concentrations of $32.4 \mathrm{ng} / \mathrm{mL}$ ( $80 \mathrm{nmol} / \mathrm{L}$ ) were needed to maximize intestinal calcium absorption (Heaney et al., 2003b). If a cut-off for vitamin D deficiency were based on maximization of calcium absorption, the majority of our population would be considered deficient in vitamin $\mathrm{D}$. It is possible that we did not observe an increase in 25-OHD with $600 \mathrm{IU} / \mathrm{d}$ due to increased hydroxylation of 25-OHD that occurs with vitamin $\mathrm{D}$ deficiency. However, we feel this is unlikely because the majority had serum PTH concentrations within the normal range.

Due to earlier developments in techniques for fortifying and quantifying vitamin $\mathrm{D}$ in process cheese, this research provides evidence of the bioavailability of such a fortification and of the feasibility of using process cheese as a method for delivering vitamin $\mathrm{D}$ to consumers. Dairy products, and vitamin D-fortified fluid milk specifically, have been considered good sources of dietary vitamin D for several years. However, the consumption of milk, particularly among the elderly, is steadily dropping (Vieth et al., 2001). In addition, there is a growing popularity of eating away from home, which is not conducive to a nutritious diet. Milk is very rarely consumed when dining out, but process cheese is used frequently in many different dishes in restaurants. Therefore, the dairy industry has another viable option for improving the nutritional status of its consumers, both young and old.

In conclusion, this study demonstrated that vitamin $\mathrm{D}$ in fortified process cheese is bioavailable but that among the elderly, consuming $600 \mathrm{IU}$ of vitamin $\mathrm{D}_{3}$ from fortified process cheese daily for 2 mo was insufficient for increasing serum total 25-OHD concentrations during negligible sunlight exposure. We also showed that elderly individuals absorb vitamin $\mathrm{D}$ as efficiently as younger individuals from both process cheese and from a water dilution, but that vitamin $\mathrm{D}$ absorption 
from process cheese was greater than from water for both age groups.

\section{ACKNOWLEDGMENTS}

We would like to thank the National Dairy Council and the South Dakota State Graduate School for partial funding of this project, and Tami Hogie-Lorenzen, Sheri Kahnke, Praveen Upreti, and Mayur Acharya for assisting in the execution of this study. Most of all we would like to thank the participants who contributed their time to make this project successful.

\section{REFERENCES}

Armas, L. A. G., B. Hollis, and R. P. Heane. 2004. Vitamin $\mathrm{D}_{2}$ is much less effective than vitamin $\mathrm{D}_{3}$ in humans. J. Clin. Endocrinol. Metab. 89:5387-5391.

Bronner, F. 1976. Vitamin D deficiency and rickets. Am. J. Clin. Nutr. 29:1307-1314.

Dabek, J. 1990. An emerging view of vitamin D. Scand. J. Clin. Lab. Invest. 50(Suppl. 201):127-133.

Gloth, M. F., C. E. Smith, B. W. Hollis, and J. D. Tobin. 1995. Functional improvement with vitamin D replenishment in a cohort of frail, vitamin D-deficient older people. J. Am. Geriatr. Soc. 43:1269-1271.

Harris, S. S., and B. Dawson-Hughes. 2002. Plasma vitamin D and 25-OHD responses of young and old men to supplementation with vitamin $\mathrm{D}_{3}$. J. Am. Coll. Nutr. 21:357-362.
Harris, S. S., B. Dawson-Hughes, and G. A. Perrone. 1999. Plasma 25-hydroxyvitamin $\mathrm{D}$ responses of younger and older men to three weeks of supplementation with $1800 \mathrm{IU} /$ day of vitamin D. J. Am. Coll. Nutr. 18:470-474.

Heaney, R. P., K. M. Davies, T. C. Chen, M. F. Holick, and M. J. Barger-Lux. 2003a. Human serum 25-hydroxycholecalciferol response to extended oral dosing with cholecalciferol. Am. J. Clin. Nutr. 77:204-210.

Heaney, R. P., S. Dowell, C. A. Hale, and A. Bendich. 2003b. Calcium absorption varies within the reference range for serum 25-hydroxyvitamin D. J. Am. Coll. Nutr. 22:142-146.

Hollis, B. W., J. Q. Kamerud, S. R. Selvaag, J. D. Lorenz, and J. L. Napoli. 1993. Determination of vitamin D status by radioimmunoassay with an ${ }^{125}$ I-labeled tracer. Clin. Chem. 39:529-533.

Holmes, R. P., and F. A. Kumerow. 1983. The relationship of adequate and excessive intake of vitamin D to health and disease. J. Am. Coll. Nutr. 2:173-199.

Kevin, K. 1997. Dean's got milk. Food Processing 58:69.

Standing Committee on the Scientific Evaluation of Dietary Reference Intakes. Food and Nutrition Board, Institute of Medicine, ed. 1997. Dietary Reference Intakes: Calcium, phosphorus, magnesium, vitamin D and fluoride. National Academy Press, Washington, DC.

Trang, H. M., D. E. C. Cole, L. A. Rubin, A. Pierratos, S. Siu, and R. Vieth. 1998. Evidence that vitamin $\mathrm{D}_{3}$ increases serum 25hydroxyvitamin $\mathrm{D}$ more efficiently than does vitamin $\mathrm{D}_{2}$. Am. J. Clin. Nutr. 68:854-858.

Upreti, P., V. V. Mistry, and J. J. Warthesen. 2002. Fortification and estimation of vitamin $\mathrm{D}_{3}$ in pasteurized process cheese. J. Dairy Sci. 85:3173-3181.

Vieth, R., P. C. R. Chan, and G. D. MacFarlane. 2001. Efficacy and safety of vitamin $\mathrm{D}_{3}$ intake exceeding the lowest observed adverse effect level. Am. J. Clin. Nutr. 73:288-294. 